\title{
Scandals have eroded US public's confidence in drug industry
}

Jeanne Lenzer New York

Only 13\% of Americans believe that pharmaceutical companies are "generally honest and trustworthy," putting the industry on a par with tobacco, oil, and managed care companies, a recent Harris Poll survey has found. Public confidence in drug companies has plunged harder and faster than for any other industry, the survey indicates (17 July, p 128).

The distrust appears to be spreading to respected US medical bodies and academic journals in the wake of a spate of public controversies concerning the influence of drug companies.

Guidelines for lowering cholesterol concentrations, issued on 12 July by the National Heart, Lung, and Blood Institute and the American Heart Association, sparked a furore when it was shown that all but one of the nine authors had financial ties to the manufacturers of cholesterol lowering drugs. The institute subsequently posted on its website the financial interests of all those involved.

Dr Barbara Alving, acting director at the institute, said that the guideline panel members had been chosen because of their "stature and track record in the field and their integrity." The guidelines were vetted by the American Heart Association and 90 other reviewers, she said, adding that leading medical experts "are also often the very people whose advice is sought by industry."

But Dr Henry Barry, senior associate chairman of the department of family practice at Michigan State University, said: "Basically what we have are [panellists] who are extrapolating data beyond what was in the studies. And when you have folks who have a financial interest, the question is, was that extrapolation influenced by their financial interests?"

Dr Michael Jacobson, executive director of the Center for Science in the Public Interest, said the failure to disclose the eight authors' competing interests in the press release and the published paper was "a travesty." He added: "I don't question the science, but this makes a mockery of disclosure rules."

The scandal comes after the publication of a study from the centre showing that the authors of 13 of 163 articles published in leading US medical journals had failed to disclose "relevant conflicts of interest."

One of the authors of a study on the sources of lead in children living near a smelter failed to acknowledge that her husband owned the smelter in question.

Hidden competing interests are probably worse than the centre's study indicated, said Dr Jacobson. "We used a very narrow definition of conflicts and we only looked at the first and last authors. In addition, we didn't have access to the authors' documents," he said.

A congressional hearing into drug companies' concealment of negative data about antidepressants for children may also have fallen foul of drug company influence. Scheduled for 20 July, it was cancelled the day before the subcommittee's chairman, Congressman James Greenwood of Pennsylvania, became president of $\mathrm{BIO}$, the largest trade organisation for biopharmaceutical companies.

Congressman Greenwood declined to respond to media inquiries about his resignation, but his office did say it believed the congressional hearings would be rescheduled.
Dr Allen Goldhammer, the associate vice president for regulatory affairs at Pharmaceutical Research and Manufacturers of America, said, "I think we need to define what influence means." He added, "Data from studies [are] audited and evaluated and go to the [Food and Drug Administration] for review. [It] has very stringent guidelines and doesn't let any of its employees have any financial interests in the industries they regulate. I don't think we should call that influence."

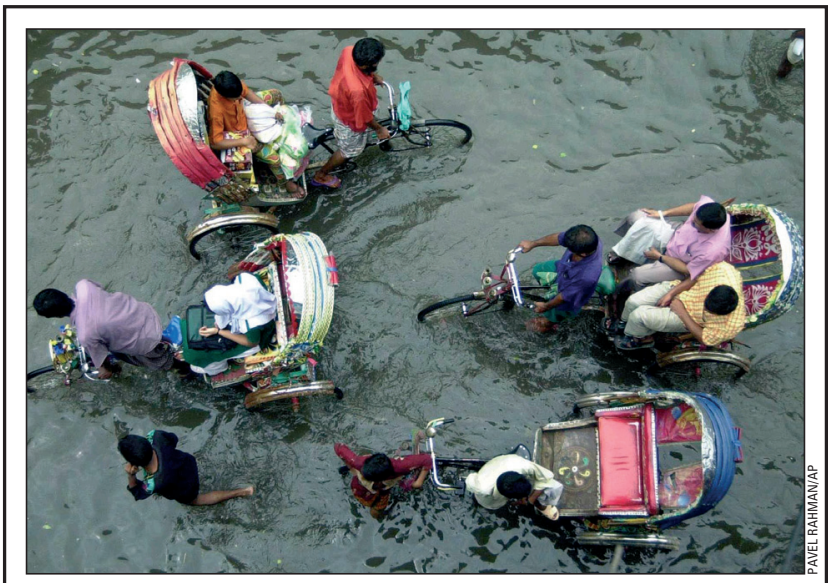

Health experts warn of disease as worst flooding in years hits Bangladesh

More than 20 million people are homeless and 300 have died from drowning, snakebite, and disease in the worst monsoon flooding to hit Bangladesh in many years.

The United Nations warned of a humanitarian crisis, and the Red Cross launched an emergency appeal as two thirds of the country and almost half the capital, Dhakar, were flooded.

Local relief officials warn that stagnant floodwater polluted with raw sewage could lead to epidemics of waterborne diseases such as dysentery, typhoid, and cholera and that a lack of access to clean water has already caused outbreaks of diarrhoea; 3500 mobile medical teams have been deployed across the country in response.

Peter Moszynski London

See www.redcross.org.uk 